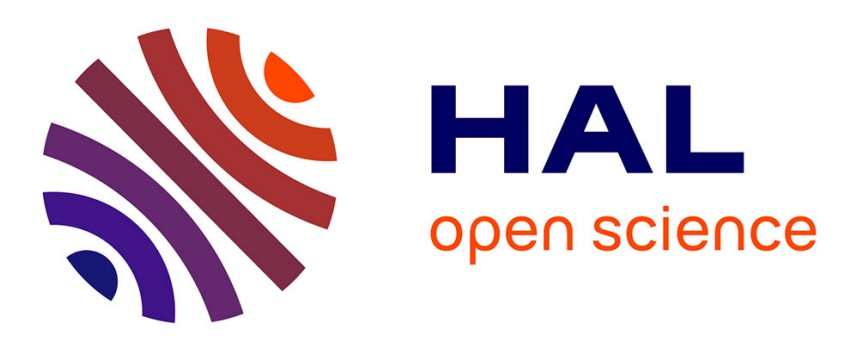

\title{
Thermoluminescence characterization of traps involved in the photodarkening of ytterbium-doped silica fibers
} Franck Mady, Mourad Benabdesselam, Wilfried Blanc

\section{To cite this version:}

Franck Mady, Mourad Benabdesselam, Wilfried Blanc. Thermoluminescence characterization of traps involved in the photodarkening of ytterbium-doped silica fibers. Optics Letters, 2010, 35 (21), pp.3541. hal-00529607

\section{HAL Id: hal-00529607 https://hal.science/hal-00529607}

Submitted on 26 Oct 2010

HAL is a multi-disciplinary open access archive for the deposit and dissemination of scientific research documents, whether they are published or not. The documents may come from teaching and research institutions in France or abroad, or from public or private research centers.
L'archive ouverte pluridisciplinaire HAL, est destinée au dépôt et à la diffusion de documents scientifiques de niveau recherche, publiés ou non, émanant des établissements d'enseignement et de recherche français ou étrangers, des laboratoires publics ou privés. 


\title{
Thermoluminescence characterization of traps involved in the photodarkening of ytterbium-doped silica fibers
}

\author{
Franck Mady, ${ }^{*}$ Mourad Benabdesselam and Wilfried Blanc \\ University of Nice-Sophia Antipolis, Laboratoire de Physique de la Matière Condensée, \\ CNRS UMR 6622, Parc Valrose, F06108 Nice cedex 2 \\ *Corresponding author: franck.mady@unice.fr
}

\begin{abstract}
Photodarkening mechanisms of ytterbium-doped silica optical fibers are still not elucidated though hardening routes have been proposed. Most basic questions are still under debate about the assignment of the darkening excitation bands into the UV range, the nature of absorbing centers (photoionized centers or trapped carriers?), or of traps accepting photoreleased carriers (electron or hole traps?). We used thermoluminescence measurements to characterize traps populated by different radiation types. It is notably demonstrated that photodarkening involves silica hole traps. The popular idea that color centers are formed upon carrier trapping is not consistent with our observations.
\end{abstract}

OCIS codes: 140.3510, 140.3615, 160.2750, 160.5690, 260.5210, 350.5610.

The performance of high output power ytterbium-doped fiber (YDF) amplifiers and lasers suffers from photodarkening (PD), a large optical loss that develops continuously under pumping (915$980 \mathrm{~nm}$ ) [1-4] or $488 \mathrm{~nm}$ radiation [5] from ultra-violet (UV) to visible ranges with significant tail at pump and gain wavelengths. PD is enhanced by high concentration and inversion rates of $\mathrm{Yb}^{3+}$ ions [1,3] and reduced by high aluminium (Al) [1] or phosphorus [4] concentrations, by cerium co-doping [6] or hydrogen loading [7]. Absorbing centers are likely to be formed after the energy of several excited $\mathrm{Yb}^{3+}$ ions was released by some process to activate photoionization. This energy being too small to bridge the gap, photoionization corresponds to the transfer of an electron (resp. hole) from a dopant or defect center to the conduction (resp. valence) band or conversely. Then, centers are oxidized or reduced whereas free electrons or holes are released that eventually trap on defects. Most workers consider colors centers are formed upon carrier trapping [5,7-10], but it has been proposed that induced absorption bands simply correspond to that of $\mathrm{Yb}^{2+}$ ions formed by the reduction of $\mathrm{Yb}^{3+}$ ions [2]. Engholm et al. $[9,10]$ consider that $\mathrm{PD}$ results from the trapping of free holes, but showed that $\mathrm{Yb}^{2+}$ ions are indeed formed upon excitation into two UV bands located at $\sim 240$ and $\sim 200 \mathrm{~nm}$ in aluminosilicate glasses (such excitation causes the same induced loss as pumping at $915 \mathrm{~nm}$ [9]). They correlated these bands to charge transfer (CT) transitions of $\mathrm{Yb}^{3+}$ ions $[9,10]$. Yoo et al. [5] assigned the UV absorption to oxygen deficient centers (ODC) after noticing that oxygen-loaded YDF exhibited lower PD. They argued the $240 \mathrm{~nm}$ excitation releases electrons that subsequently trap at $\mathrm{Al}$ - or Yb-sites to form color centers [5] and discussed the PD behaviour at high temperature on this basis [8]. The existence of the UV absorption pattern in Yb-free fused silica was reported more than 50 years ago, the $\sim 240 \mathrm{~nm}$ band being already found to be suppressed by oxidization [11]. The debate on CT/ODC assignments [12,13] is therefore legitimate. Basic disagreements also remain on the actual nature of absorbing centers (trapped carriers or reduced/oxidized ions?) and of involved 
traps (electron or holes traps?). This work provides conclusive results based on the trap characterization by thermally stimulated luminescence (TSL).

TSL consists of photons emitted upon radiative recombination of 'detrapped' carriers with carriers of opposite polarity on reduced/oxidized centers (recombination centers). After radiation exposure, samples are heated up linearly $\left(1^{\circ} \mathrm{C} \mathrm{s}^{-1}\right)$ and carriers are thermally released from traps of increasing depths. The TSL collected with a photomultiplier tube is plotted as a function of temperature to give the 'glow curves' that reflect the distribution of non-luminescent traps populated by irradiation. Glow curves exhibit peaks. Each single trapping level gives rise to a single peak (the deeper the trap, the higher the peak temperature). TSL spectra acquired at any temperature with an optical multi-channel analyzer reveal the recombination centers at play, thus allowing the identification of photoionized luminescent centers.

Samples consisted of $\sim 4 \mathrm{~mm}$ radius and 1-2 mm thick discs cut out from optical fiber preforms made in our laboratory by modified chemical vapour deposition (MCVD) and solution doping. Samples with Yb-free aluminosilicate core (referred to as AS, $4 \mathrm{~mol} \% \mathrm{Al}$ ), Yb-doped alumino-silicate cores (AS:Yb, $0.4 \mathrm{~mol} \% \mathrm{Yb}, 4 \mathrm{~mol} \% \mathrm{Al}$ ) and $\mathrm{Yb}$-free germanosilicate core (GS, $10 \% \mathrm{GeO}_{2}$ ) have been considered. Samples were photo-darkened by in-core irradiation with an $\mathrm{Ar}^{+}$ion laser (488 and $514 \mathrm{~nm}$ lines) at $645 \mathrm{~mW} \mathrm{~mm}{ }^{-2}$ and by UV photons from a $50 \mathrm{~W}$ deuterium lamp, through Oriel interferential filters centered at 206 and $250 \mathrm{~nm}$ (27 and $13 \mathrm{~nm}$ FWHM respectively) with a constant energy fluence. For comparison, $45 \mathrm{kV}$ X ray irradiations at $30 \mathrm{~Gy} \mathrm{~min}^{-1}$ were also employed to ensure band-to-band injection. Core optical absorptions were measured with a Cary 500 spectrophotometer before and after irradiation to obtain the radiation-induced loss. Details of the TSL apparatus are presented elsewhere (see e.g. [14]).

Figure 1 displays the glow plots of the AS: $\mathrm{Yb}$ and GS samples after laser and $\mathrm{X}$ ray irradiation. Plots have been normalized with respect to their maximum because radiation doses are not identical. The most general feature we observe for a variety of samples is shown by the GS curve: 3 main TSL broad peaks appear around $150^{\circ} \mathrm{C}$ (referred to as peak 1), $275^{\circ} \mathrm{C}$ (peak 2), and $450^{\circ} \mathrm{C}$ (peak 3), showing that three distinguishable groups of trapping levels are populated. Unfortunately the third peak is poorly resolved for the AS:Yb sample because the TSL signal was not intense enough to be extracted from the background black body emission which yields a continuous steep increase of the luminescence above $400^{\circ} \mathrm{C}$. This emission has been subtracted for the displayed curves, but the correction leaves nothing but noise when applied on weak signals (AS:Yb-related plots are not exploitable above $400{ }^{\circ} \mathrm{C}$ ).

For the AS:Yb sample, similar peaks are present at same temperatures after $\mathrm{X}$ and $\mathrm{Ar}^{+}$ion laser irradiations in figure 1. In figure 2, the TSL plots obtained after laser, $250 \mathrm{~nm}(4.96 \mathrm{eV})$ or $206 \mathrm{~nm}$ ( $6 \mathrm{eV}$, inset) photon exposures also exhibit similar peaks. Therefore carriers excited under the $\sim 2.5 \mathrm{eV}$ laser photons, the $6 \mathrm{eV}, 4.96 \mathrm{eV}$ or $\mathrm{X}$ radiations eventually populate the same traps in the AS:Yb sample. Relative intensities of peaks 1 and 2 depend on the radiation type. When samples are irradiated with $\mathrm{X}$ rays or the UV lamp, both core and cladding regions are submitted to the radiation and participate in glow curves. By contrast, the laser beam was focused in the sample core so no TSL is emitted from the cladding. It thus appears that the first and second TSL peaks are particularly related to the preform cladding and core respectively, even if traps related to both peaks are obviously present throughout the sample. In figure 2, the 6 eV excitation (206 nm, inset) leads to large TSL signals, i.e. to significant trap filling, for all of the AS, GS and AS:Yb samples. The $4.95 \mathrm{eV}$ and $\sim 2.5 \mathrm{eV}$ radiations populate traps in the AS: $\mathrm{Yb}$ preform only since there is virtually no TSL from AS and GS samples in these cases. We therefore conclude that: (i) a $>5-6 \mathrm{eV}$ energy is required to achieve ionization in AS and GS 
samples, which probably corresponds to their gap energy, (ii) $\mathrm{Yb}^{3+}$ ions are responsible for subgap excitation into the $\sim 5 \mathrm{eV}$ UV band or by the $\sim 2.5 \mathrm{eV}$ laser photons. In the TSL curve of AS:Yb after $206 \mathrm{~nm}$ excitation (figure 2, inset), the intensity ratio peak 1/peak 2 is greater than unity because traps are populated both in core and cladding, as for X rays (figure 1). By contrast, the $250 \mathrm{~nm}$ radiation which cannot populate traps in the absence of $\mathrm{Yb}^{3+}$ ions only fills the core traps. Then, the second TSL peak is more intense than the first one, as for the laser irradiation. The good concordance between the TSL peaks obtained after $\sim 5 \mathrm{eV}$ and $\sim 2.5 \mathrm{eV}$ irradiations (figure 2) suggests the effects of both radiations are simply similar, confirming the result of Yoo et al. [5] that a 2 photon absorption takes place. Point (ii) also supports the idea that $\mathrm{Yb}^{3+}$ ions have an absorption band at $\sim 5 \mathrm{eV}$ (lower CT band in [9]).

After reading out the TSL of the AS:Yb samples at $1^{\circ} \mathrm{C} \mathrm{s}^{-1}$ up to $550-600^{\circ} \mathrm{C}$ we observe the optical transmission of non-irradiated cores is totally recovered (bleaching by linear heating has also been considered in [15]). This demonstrates that optical recovery well follows the emptying of the traps revealed by TSL. Optical losses induced in the core of the AS:Yb sample by argon laser and $\mathrm{X}$ rays are shown in figure 3. The laser-induced bands at $3.1 \mathrm{eV}, 3.8 \mathrm{eV}, 4.7 \mathrm{eV}$ and 5.3 $\mathrm{eV}$ are in good agreement with the absorption bands assigned to $\mathrm{Yb}^{2+}$ ions [10,16]. In [10], these ions are shown to have an additional $6 \mathrm{eV}$ absorption band which seems to be shifted at $\sim 6.4 \mathrm{eV}$ here. However, our absorption measurements are probably inaccurate in the $>5.5 \mathrm{eV}$ region due to the strong UV absorption by our thick samples. The origin of our laser-induced bands around $2.4 \mathrm{eV}$ is currently investigated. If $\mathrm{Yb}^{2+}$ ions are actually formed by the laser radiation, traps associated with the TSL peaks are necessarily hole traps. This is confirmed by the inset of figure 1 , where the TSL from the AS: $\mathrm{Yb}$ core is shown to consist of $\mathrm{Yb}^{3+}$ ions emission throughout the TSL temperature range. The recombination process at play upon detrapping is hence $\mathrm{Yb}^{2+}+$ hole $\rightarrow \mathrm{Yb}^{3+}+$ characteristic emission (possibly a quenched CT relaxation [10,17]). As a result, $\mathrm{X}$ rays produce $\mathrm{Yb}^{2+}$ ions and populate hole traps, the same as those filled by the $\mathrm{Ar}^{+}$ion laser as proved by the peak correspondence of figure 1 . However, induced losses are not similar for $\mathrm{X}$ and laser radiations (figure 3). Specific absorbing centers are formed under X excitation, notably in the 2.5-4.5 eV range. When the dose exceeds $~ 300 \mathrm{~Gy}$, PD becomes apparent to the naked eye. The inset of figure 3 shows that darkening only affects the preform core. The latter consists of MCVD-deposited silica, as the surrounding cladding layers which remain transparent though also submitted to $\mathrm{X}$ rays. The darkening effect is therefore specific to the core dopants, $\mathrm{Yb}$ or Al.

The hypothesis that color centers responsible for PD are formed upon trapping of free carriers fails according to the present results. First, X-rays induce specific absorption patterns compared with $\mathrm{Ar}^{+}$ion laser whereas both radiation type populate the same traps (no specific trap is revealed by TSL plots of the X-irradiated AS:Yb sample). Second, the GS and AS:Yb samples present the same TSL peaks, i.e. the same populated traps, but the GS preform was never found to darken, even after high radiation doses. The same applies for the cladding of the $\mathrm{AS}: \mathrm{Yb}$ preform where $\mathrm{X}$ rays populates traps without leading to darkening. According to TSL plots in figure 1 and 2 (inset), the same traps are populated by ionizing radiations in AS:Yb, GS and AS samples. These traps cannot be related to $\mathrm{Al}, \mathrm{Yb}$ or Ge but must primarily correspond to defects of the silica matrix. By contrast, $\mathrm{PD}$ requires the presence of $\mathrm{Yb}$ or $\mathrm{Al}$, even when high energy photons (UV or $\mathrm{X}$ ) are able to inject free carriers regardless of the presence of $\mathrm{Yb}$.

This work shows that PD involves intrinsic silica hole traps but that the populated traps are not the main color centers responsible for darkening. Radiation-induced loss results primarily from absorption by reduced $\mathrm{Yb}$ - and Al-related centers, including $\mathrm{Yb}^{2+}$ ions. The crucial role of $\mathrm{Yb}^{3+}$ ions in the radiation absorption, trap filling and PD development under sub-gap excitation 
is confirmed. The fact that photoionization mainly releases holes and not electrons supports the proposal by Engholm et al. [9,10,12] that the $240 \mathrm{~nm}$ absorption band correspond to a CT transition rather than to an ODC excitation. The $200 \mathrm{~nm}$ CT band of [9] is not confirmed because $6 \mathrm{eV}$ photons bridge the gap of all examined samples. Free holes produced under high energy $\mathrm{X}$ or UV (6 eV) excitation eventually trap on the same trapping levels as holes released by the $250 \mathrm{~nm}$ or $488-514 \mathrm{~nm}$ radiations. It is therefore not necessary to discriminate between holes created by excitation into the $\sim 240 \mathrm{~nm}$ and $\sim 200 \mathrm{~nm}$ bands respectively as proposed in [9].

\section{References}

1. T. Kitabayashi, M. Ikeda, M. Nakai, T. Sakai, K. Himeno, and K. Ohashi, "Population inversion factor dependence of photodarkening of Yb-doped fibres and its suppression by highly aluminum doping”, in Optical Fiber Communication Conference, Vols. 1-6 (Optical Society of America, 2006), paper OthC5.

2. A.D. Guzman Chávez, A.V. Kir’yanov, Y.O. Barmenkov, and N.N. Il’ichev, "Reversible photo-darkening and resonant photo-bleaching of ytterbium-doped silica fibre at in-core 977nm and 543-nm irradiation”, Laser Phys. Lett. 4, 734-739 (2007).

3. S. Jetschke, S. Unger, U. Röpke, and J. Kirchhof, "Photodarkening in Yb doped fibres: experimental evidence of equilibrium states depending on the pump power", Opt. Express 15, 14838-14843 (2007).

4. S. Suzuki, H.A. McKay, X. Peng, L. Fu, and L. Dong, "Highly ytterbium-doped silica fibres with low photo-darkening”, Opt. Express 17, 9924-9932 (2009).

5. S. Yoo, C. Basu, A.J. Boyland, C. Sones, J. Nilsson, J.K. Sahu and D. Payne, "Photodarkening in Yb-doped aluminosilicate fibres induced by $488 \mathrm{~nm}$ irradiation", Opt. Lett. 32, 1626-1628 (2007).

6. M. Engholm, P. Jelger, F. Leurell and L. Norin, "Improved photodarkening resistivity in ytterbium-doped fiber lasers by cerium co-doping”, Opt. Lett. 34, 1285-1287 (2009).

7. M. Engholm and L. Norin, "Reduction of photodarkening in Yb/Al-doped fiber lasers", Proc. SPIE 6873, 269-276 (2008).

8. S. Yoo, A.J. Boyland, R.J. Standish and J.K. Sahu, "Measurements of photodarkening in Yb doped aluminosilicate fibres at elevated temperatures", Electron. Lett. 46, 233-234 (2010).

9. M. Engholm and L. Norin, "Preventing photodarkening in ytterbium-doped high power fiber lasers; correlation to the UV transparency of the core glass", Opt. Express. 16, 1260-1268 (2008).

10. M. Engholm, L. Norin and D. Åberg, "Strong UV absorption and visible luminescence in ytterbium-doped aluminosilicate glass under UV excitation”, Opt. Lett. 32, 3352-3354 (2007).

11. W.H. Turner and H.A. Lee, "Absorption, luminescence and excitation spectra of "reduced" fused silica”, J. Chem. Phys. 43, 1428-1429 (1965).

12. M. Engholm and L. Norin, "Comment on "Photodarkening in Yb-doped aluminosilicate fibres induced by $488 \mathrm{~nm}$ irradiation””, Opt. Lett. 33, 1216 (2008).

13. S. Yoo, C. Basu, A.J. Boyland, C. Sones, J. Nilsson, J.K. Sahu and D. Payne, "Reply to comment on "Photodarkening in Yb-doped aluminosilicate fibres induced by $488 \mathrm{~nm}$ irradiation””, Opt. Lett. 33, 1217-1218 (2008). 
14. M. Benabdesselam, A. Petitfils, F. Wrobel, F. Mady, and J.E. Butler, "Thermal quenching investigation in CVD diamond by thermally stimulated conductivity and luminescence”, $\mathrm{J}$. Appl. Phys. 103, 114908 (2008).

15. M. Leich, U. Röpke, S. Jetschke, S. Unger, V. Reichel, and J. Kirchhof, "Non-isothermal bleaching of photodarkened Yb-doped fibers", Opt. Express 17, 12588-12593 (2009).

16. J. Kirchhoff, S. Unger, A. Schwuchow, S. Grimm and V. Reichel, "Materials for high-power fiber lasers”, J. Non-Cryst. Sol. 352, 2399-2403 (2006).

17. P. Dorenbos, "Systematic behaviour in trivalent lanthanide charge transfer energies", J. Phys.: Condens. Matter 15, 8417-8434 (2003). 


\section{Figure captions}

1. Glow plots of $\mathrm{AS}: \mathrm{Yb}$ and GS samples after $\mathrm{X}$ or $\mathrm{Ar}^{+}$ion laser irradiation. Inset: typical TSL spectrum of the core of the AS:Yb sample (spectral components are found to remain unchanged throughout the glow plot).

2. Glow plots of AS:Yb, AS and GS samples after $250 \mathrm{~nm}$ or $\mathrm{Ar}^{+}$ion laser irradiation. Inset: idem after irradiation at $206 \mathrm{~nm}$.

3. Optical losses induced by $\mathrm{X}$ or $\mathrm{Ar}^{+}$ion laser irradiations. Dotted lines show the Gaussian peak deconvolution of the laser-induced bands. Inset: photograph of the AS:Yb sample after a 500 Gy X ray irradiation; the darkened zone corresponds to the large preform core. 


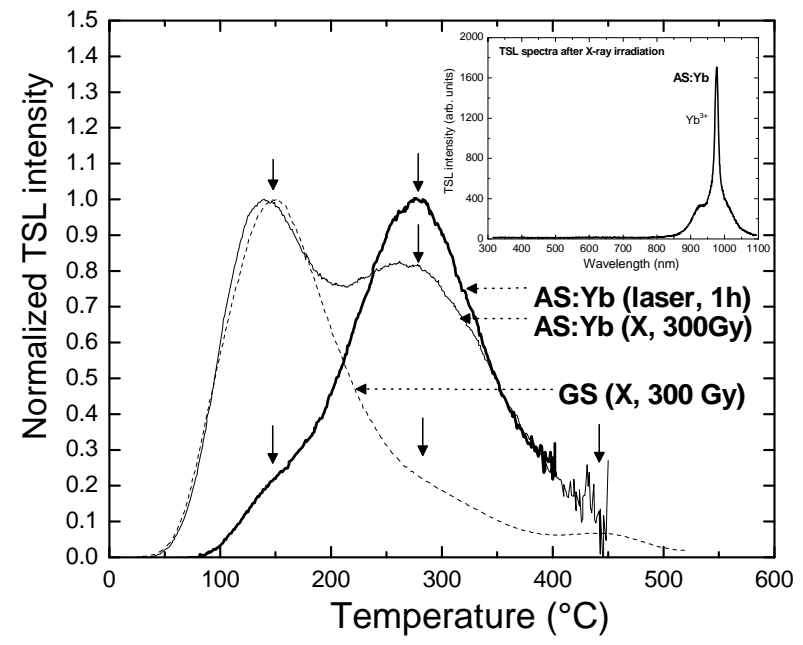

Figure 1 


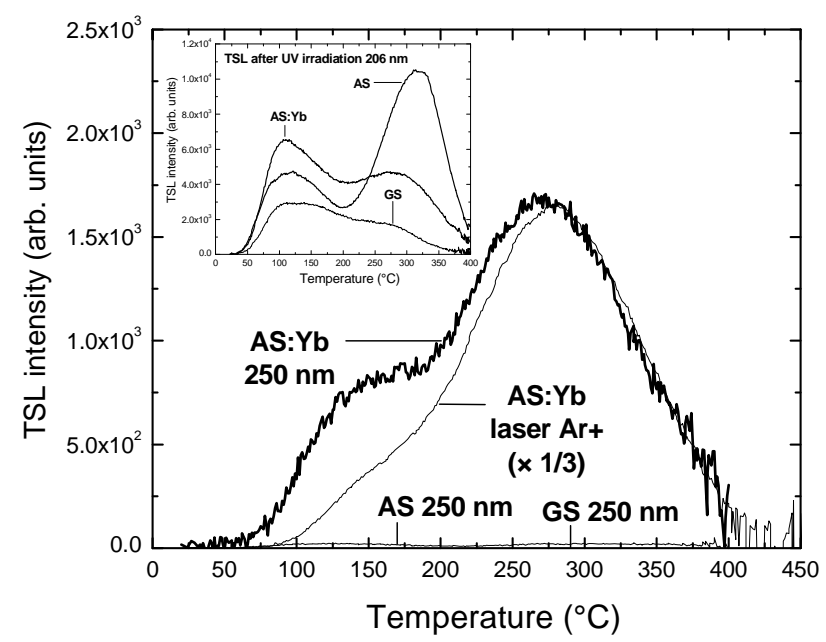

Figure 2 


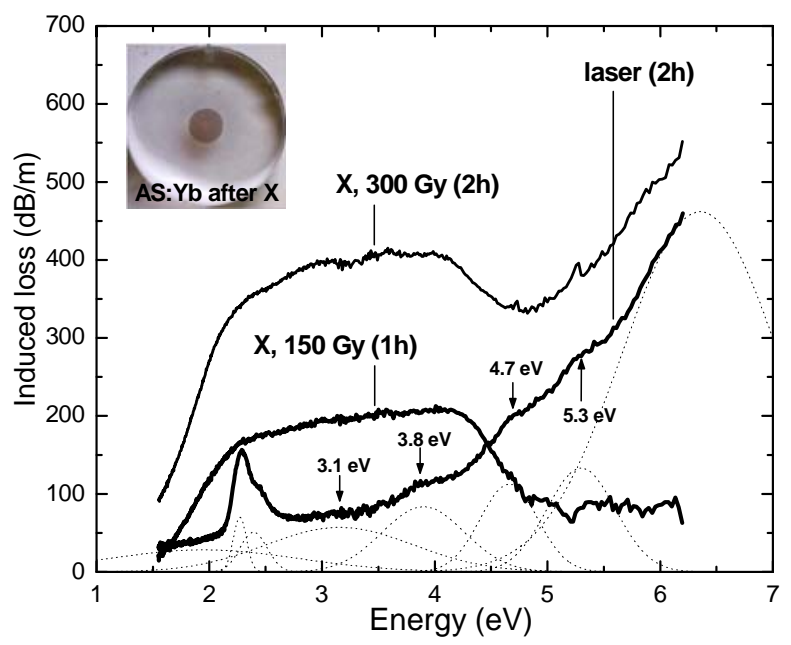

Figure 3 